\title{
Compare the Outcomes of Mini-Plate versus K-Wire Fixation in Patients with Shaft of Metacarpal Fractures
}

\author{
FRAZ NOOR ${ }^{1}$, HAFIZ MUHAMMAD NASIR ${ }^{2}$, FARTASH ZAHRA ${ }^{3}$, JUGDESH KUMAR ${ }^{4}$, SIKANDAR ALI $^{5}$ \\ ${ }^{1}$ Assistant Professor Orthopaedic, Sahara Medical College, Narowal \\ ${ }^{2}$ Consultant Orthopaedic Surgeon, DHQ Hospital, Narowal \\ ${ }^{3}$ House Officer, Medical Unit-2 Lahore General Hospital, Lahore \\ ${ }^{4}$ Professor of Orthopaedic, Chandka Medical College, Shaheed Mohtarma Benazir Bhutto Medical University, Larkana \\ ${ }^{5}$ Assistant Professor, Department of Orthopaedic \& Trauma Surgery, Indus Medical College Hospital, Tando Muhammad Khan \\ Correspondence to: Dr. Fraz Noor, E-mail:drfraznoor@gmail.com, Cell: 0331-4548771
}

\begin{abstract}
Objective: To compare the functional outcomes of K-wire versus mini plate fixation for the treatment of fractures shaft of metacarpal.

Study Design: Randomized controlled trial

Place and Duration of Study: Department of Orthopaedic, Sahara Medical College, Narowal from $1^{\text {st }}$ August 2020 to $31^{\text {st }}$ January 2021.

Methodology: Fifty six patients of both genders presented with fractures shaft of metacarpal were included. Patient's ages were ranging between 15 to 60 years. Radiographic assessment was done to all the patients. Patients were categorized in to two equal groups. 28 patients treated with mini plates (group A) and 28 patients treated with K-wire fixation (group B). Post-operative complications were examined and compare between both groups. DASH scoring system was used for analyzing functional outcomes.

Results: Mean age in group A was $34.57 \pm 7.84$ years and in group B it was $34.95 \pm 7.76$ years. Majority of patients $18(64.29 \%)$ and $17(60.71 \%)$ were males in group A and B. Mean time of union in group A was 9.58 \pm 2.24 weeks while in group B it was $12.33 \pm 2.85$ weeks, the difference was statistically significant ( $p$-value $<0.05)$. As per DASH criteria, $15(57.14 \%), 11(39.29 \%)$ and $2(7.14 \%)$ patients had excellent, good and fair functional outcomes who treated with mini plates internal fixation, while in group B $12(42.86 \%), 13(46.43 \%), 2(7.14 \%)$ and $1(3.57 \%)$ patients had excellent, good, fair and poor functional outcomes. Postoperative complications were more in group $B$ as compared to group A but the difference was not statistically significant ( $p$-value $>0.05$ ).

Conclusion: Both procedures mini-plate internal fixation and K-wire fixation are effective for fractures shaft of metacarpal. However, mini-plates showed better functional outcomes with fewer rate of postoperative complications and earlier union as compared to K-wire internal fixation.
\end{abstract}

Keywords: Shaft of metacarpal fracture, Internal fixation, Mini-plate, K-wire, DASH scoring system

\section{INTRODUCTION}

Metacarpal bone fractures are one of the most common orthopaedic injuries, accounting for around $10 \%$ of the total fractures and the most common hand fractures up to $40 \%{ }^{1}$ 3 The metacarpals are long tiny, slightly arched bones on the longitudinal axis and concave on the flying surface. Only behind the skull is the weakest region. 4,5

Metacarpal fractures may be worsened by therapeutic neglect, over-training rigidity and maltreatment deformity and rigidity. ${ }^{6}$ The goals of treatment include early diagnosis, reduction of rotational anatomy and deformities, soft-tissue preservation, preservation of the longitudinal and transversal arches and maintenance of metacarpus length as a result of shortening by more than $3 \mathrm{~mm}$ the external and intrinsically handled muscles are imbalanced. ${ }^{7}$

Hand fractures have been improved because to better materials, implant design, instruments, a better understanding of the biomechanics of internal fixation, the availability of hand surgeon subspecialists, ease of anaesthetic, and the enhancement of hand-physiotherapy methods. 8,9

The treatment of metacarpal fractures has expanded considerably over the last 25 years. Closed reduction and splinting can be handled, which is disadvantageous since it is difficult to keep joint motion to prevent stiffness. ${ }^{10}$ The fixation of the Kirschner wires, the intraosseous wiring and the fixation of the screw by or without the plate benefit from early active motion but from the disadvantage of large surgical exposure and soft tissue damage. ${ }^{11}$

We conducted present study with aimed to compare the functional outcomes of mini-plate versus K-wire for shaft of metacarpal fractures.

\section{MATERIALS AND METHODS}

This randomized controlled trial was conducted at Department of Orthopaedic, Sahara Medical College, Narowal from $1^{\text {st }}$ August 2020 to $31^{\text {st }}$ January 2021. A total of 56 patients of both genders presented with fractures shaft of metacarpal were included in this study. Patient's detailed demographics including age, sex, type of fracture, and side of fracture were recorded after taking informed written consent. Comminuted shaft and condylar fractures, metacarpal fractures in children $<18$ years old, old Metacarpal fractures, and patients with open fractures were excluded.

Pre and postoperatively complete radiological assessment was done. Patients were categorized in to two equal groups. Twenty patients treated with mini plates (group A) and 28 patients treated with K-wire fixation (group B). Post-operative complications such as superficial infection, delayed union, and finger stiffness were examined. Post-operative complications were examined and compare between both groups. DASH scoring system 
was used for analyzing functional outcomes. Patients were followed for 12 weeks.

All the data was analyzed by SPSS 24.0. Chi-square test was done to compare the functional outcomes and postoperative complications between both groups. P-value $<0.05$ was taken as significant.

\section{RESULTS}

Mean age in group A was $34.57 \pm 7.84$ years and in group $B$ it was $34.95 \pm 7.76$ years. Majority of patients $18(64.29 \%)$ and $17(60.71 \%)$ were males in group $A$ and $B$ while 10 (35.71\%) and $11(39.29 \%)$ patients were females in group A and B. In group A and B 16 (57.14\%) and 15 (53.57\%) patients had right side fractures while $12(42.86 \%)$ and 13 (46.43\%) patients had left side fractures. 19 (67.86\%), 6 $(21.43 \%)$ and $3(10.71 \%)$ patients in group $A$ had transverse, oblique and spiral fracture shape while in group B $20(71.43 \%)$ patients had transverse, $5(17.86 \%)$ had oblique and $3(10.71 \%)$ had spiral fractures (Table 1).

Mean time of union in group A was $9.58 \pm 2.24$ weeks while in group B it was $12.33 \pm 2.85$ weeks, the difference was statistically significant $(p$-value $<0.05)$. In group $B 1$ (3.57\%) patient had non union while in group $B$ none of patient had non-union of bone (Table 2).

As per DASH criteria, 15 (57.14\%), 11 (39.29\%) and $2(7.14 \%)$ patients had excellent, good and fair functional outcomes who treated with mini plates internal fixation, while in group B 12 (42.86\%), 13 (46.43\%), 2 (7.14\%) and $1(3.57 \%)$ patients had excellent, good, fair and poor functional outcomes (Table 3).

Table 1: Demographic information of the participants

\begin{tabular}{|l|l|l|}
\hline Variable & Group I & Group II \\
\hline Age & $34.57 \pm 7.84$ & $34.95 \pm 7.76$ \\
\hline Gender & $18(64.29 \%)$ & $17(60.71 \%)$ \\
\hline Male & $10(35.71 \%)$ & $11(39.29 \%)$ \\
\hline Female & $12(42.86 \%)$ & $13(46.43 \%)$ \\
\hline Fracture side & $16(57.14 \%)$ & $15(53.57 \%)$ \\
\hline Left & \multicolumn{2}{|l|}{} \\
\hline Right & $19(67.86 \%)$ & $20(71.43 \%)$ \\
\hline Fracture shape & $6(21.43 \%)$ & $5(17.86 \%)$ \\
\hline Transverse & $3(10.71 \%)$ & $3(10.71 \%)$ \\
\hline Oblique &
\end{tabular}

Table 2: Union time of bone and non-union

\begin{tabular}{|l|l|l|l|}
\hline Variable & Group A & Group B & P-value \\
\hline Union time (weeks) & $9.58 \pm 2.24$ & $12.33 \pm 2.85$ & 0.018 \\
\hline Non-union & - & $1(3.57 \%)$ & N/S \\
\hline Union of Bone & $28(100 \%)$ & $27(96.43 \%)$ & N/S \\
\hline
\end{tabular}

Table 3: Functional outcomes as per DASH scoring system

\begin{tabular}{|l|l|l|}
\hline Variable & Group I & Group II \\
\hline Excellent & $15(57.14 \%)$ & $12(42.86 \%)$ \\
\hline Good & $11(39.29 \%)$ & $13(46.43 \%)$ \\
\hline Fair & $2(7.14 \%)$ & $2(7.14 \%)$ \\
\hline Poor & $0(0)$ & $1(3.57 \%)$ \\
\hline
\end{tabular}

P-value $>0.05$

In group A, $3(10.71 \%)$ patients had superficial infection, $2(7.14 \%)$ had stiffness, 1 (3.57\%) patient had implant loosening while none of patient had delayed union while in group B $4(14.29 \%)$ patients had superficial infection, $3(10.71 \%)$ had finger stiffness, 2 (7.14\%) patients had implant loosening and 1 (3.57\%) patient had delayed union. Postoperative complications were more in group B as compared to group A but the difference was not statistically significant ( $p$-value $>0.05$ ) [Table 4].

Table 4: Comparison of postoperative complications between both groups

\begin{tabular}{|l|l|l|}
\hline Variable & Group I & Group II \\
\hline Superficial infection & $3(10.71 \%)$ & $4(14.29 \%)$ \\
\hline Finger stiffness & $2(7.14 \%)$ & $3(10.71 \%)$ \\
\hline Implant Loosening & $1(3.57 \%)$ & $2(7.14 \%)$ \\
\hline Delayed union & - & $1(3.57 \%)$ \\
\hline P-value $>0.05$ &
\end{tabular}

\section{DISCUSSION}

Fractures shaft of metacarpal bone are commonly encountered fractures in orthopaedic settings. Many of surgical modalities have been applied for the treatment of these fractures but mini-plate fixation and internal fixation with K-wire are the most performing procedures due to high rate of excellent functional outcomes and fewer rates of complications. ${ }^{12,13}$ Majority of patients were male in both groups and overall accounted $62.5 \%$ while $37.5 \%$ were females. Overall mean age in our study was $35.46 \pm 8.58$ years. Studies demonstrated that males patients were more who had fracture shaft of metacarpal and the average age of patients was 30 years. ${ }^{14,15}$

In present study, we found that Mean time of union in group A (mini-plates) was 9.58 \pm 2.24 weeks while in group $\mathrm{B}$ (K-wire fixation) it was $12.33 \pm 2.85$ weeks, the difference was statistically significant $(p$-value $<0.05)$. In group $B 1$ $(3.57 \%)$ patient had non union while in group $B$ none of patient had non-union of bone. A study conducted by Agarwal et al $^{16}$ reported that time of union was better in patients received mini plate as compared to patients with $\mathrm{k}$ wire fixation but the results were statistically insignificant.

A study conducted by Ahmad et $\mathrm{al}^{17}$ reported that patients received mini-plates had shorter time of union of bone as compared to those who received $\mathrm{K}$-wire fixation

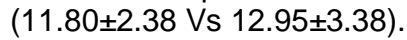

Another study by Abdel-hamid et $\mathrm{al}^{18}$ reported that patients treated with mini-plates the average union time was 6 weeks as compared to K-wire with 8 weeks.

As per DASH criteria, 15 (57.14\%), 11 (39.29\%) and $2(7.14 \%)$ patients had excellent, good and fair functional outcomes who treated with mini plates internal fixation, while in group B, 12 (42.86\%), 13 (46.43\%), 2 (7.14\%) and $1(3.57 \%)$ patients had excellent, good, fair and poor functional outcomes Agarwal et $\mathrm{al}^{16}$ reported that patients received mini plate fixation had better functional outcomes as compared to k-wire fixation.

Khaled et $\mathrm{al}^{19}$ reported that $93.3 \%$ patients had satisfactory functional outcomes who received mini-plates while $86.7 \%$ patients with $\mathrm{K}$-wire fixation had satisfactory outcomes.

In our study postoperative complications were more in k-wire fixation group as compared to mini-plates group, but the difference was not statistically significant $(p>0.05$. We found that among group A (mini-plate), 3 (10.71\%) patients had superficial infection, 2 (7.14\%) had stiffness, 1 (3.57\%) patient had implant loosening while none of patient had delayed union while in group B (k-wire fixation) 4 (14.29\%) patients had superficial infection, $3(10.71 \%)$ had finger 
stiffness, $2(7.14 \%)$ patients had implant loosening and 1 $(3.57 \%)$ patient had delayed union. These results showed similarity to many of previous studies in which mini-plate fixation were associated with fewer rate of complications as compared to k-wire fixation. ${ }^{20,21}$

\section{CONCLUSION}

Both mini-plate internal fixation and K-wire fixation procedures are effective for fractures shaft of metacarpal. However, mini-plates showed better functional outcomes with fewer rate of postoperative complications and earlier union as compared to K-wire internal fixation.

\section{REFERENCES}

1. Avery DM $3^{\text {rd }}$, Rodner CM, Edgar CM. Sports-related wrist and hand injuries. a review. J Orthop Surg Res 2016; 11: 199.

2. Rocchi, Lorenzo, Merendi, et al. Antegrade percutaneous intramedullary fixation technique for metacarpal fractures: a prospective study on 150 cases. Techniques Hand Upper Extremity Surg 2018: 22.3, 104-109.

3. Barnett R, BrodskyR. Dorsally-displaced metacarpal dislocation-fracture. J Educ Teaching Emerg Med 2018; 3: 3.

4. Kaplan, Emanuel B. Functional and surgical anatomy of the hand. JP Lippincott 1965.

5. Howard Jr, Lot D. Fractures of the small bones of the hand. Plastic Reconstruct Surg 1962; 29(4): 334-5.

6. Venkatesh R, Kerakkanavar S. Functional outcome of closed metacarpal shaft fractures managed by low-profile miniplate osteosynthesis: a prospective clinical study. J Orthop Spine 2017; 5: 2

7. Bryan BK, Kohnke EN. Therapy after skeletal fixation in the hand and wrist. Hand Clin 1997; 13(4): 761-76.

8. Carreño A, Ansari MT, Malhotra R. Management of metacarpal fractures. J Clin Orthop Trauma 2020.

9. Pandey R, Soni N, Bhayana H, Malhotra R, Pankaj A, Arora $S S$, et al. Hand function outcome in closed small bone fractures treated by open reduction and internal fixation by mini plate or closed crossed pinning: a randomized controlled trail. Musculoskelet Surg 2019; 103(1): 99-105.
10. Gupta R, Kumar K, Rakesh. A prospective study to analyse various methods of surgical fixation of metacarpal \& phalangeal fractures. Int J Orthop 2018; 4(2): 658-63.

11. Soni A, Gulati A, Bassi JL, Singh D, Saini UC. Outcome of closed ipsilateral metacarpal fractures treated with mini fragment plates and screws: a prospective study. J Orthop Traumatol 2012; 13(1): 29-33.

12. Wang, MZ. Comparison of miniature plate and Kirschner wire fixation on the treatment of metacarpal and phalangeal fractures. Chinese J Contemp Med 2011; 17: 149.

13. Yang, JG, Huang, Y, Cui, JD. Observation of the effects on Kirschner and mini-plate fixation of metacarpal and phalangeal fractures. Chinese J Med Front 2013; 9: 150-51.

14. Chen XJ. Efficacy of micro-plate and Kirschner wire fixation on the treatment of metacarpal and phalangeal fractures. Chinese Med Pharmacy 2018; 1: 228-30.

15. von Kieseritzky J, Nordström J, Arner M. Reoperations and postoperative complications after osteosynthesis of phalangeal fractures: a retrospective cohort study. J Plast Surg Hand Surg 2017;51:458-62.

16. Agarwal BK, Ravikumar AS, Sridhar DK. A prospective study of functional outcome between Mini-plates and percutaneous K-wire fixation following metacarpal shaft fractures. Int $\mathrm{J}$ Orthop Sci 2019;5(4):328-31.

17. Ahmed Z, Haider M, Buzdar $M$, et al. Comparison of miniplate and K-wire in the treatment of metacarpal and phalangeal fractures. Cureus 2020: 12(2): e7039.

18. Abdel-hamid M, Abulsoud M, Bissar M. Comparative study between intramedullary $\mathrm{K}$ wires versus mini-plates and screws in fixation of metacarpal shaft fractures in adults. AlAzhar Int Med J 2020; 1(12): 299-305.

19. Nour AK, Elalfy M. Unstable metacarpal fractures: a comparative study between mini-plates and percutaneus kwire fixation at Emergency Hospital, Mansoura University, Egypt. Orthop Rheum Open Access J 2018; 13(2): 555859.

20. Vasileios V, Catherine JS, Malack $H$, Hassan $H$, Brian $P$. Extraarticular metacarpal fractures: closed reduction and percutaneous pinning versus open reduction and internal fixation. Plastic Reconstruc Surg 2019; 7 (5): pe2261.

21. Ahmad T, Khan J, Ahmad R, Sheraz M, Rehman OU. K wires versus plating in metacarpal and phalangeal fractures a randomized control trila to compare the range of motion after these modes of treatment. Isra Med J 2018;10(2):70-3. 